\title{
TERMS AS UNITS OF TRANSLATION
}

\section{Yuliia Sydorenko ${ }^{1}$}

DOI: https://doi.org/10.30525/978-9934-26-077-3-19

Abstract. The purpose of the paper is to determine the features of the translation of technical terms from English into Ukrainian. A term is a word or phrase that expresses a clearly defined concept in a particular field of science, technology, art, socio-political life, and so on. Scientific and technical terminology is a wide layer of vocabulary that develops intensively and actively interacts with other layers of the vocabulary of the language, primarily with common vocabulary. Unlike commonly used words, terms are usually unambiguous, they are not characterized by expression. Some terms have lost a purely special character and are widely used in various parts of speech, while others retain a narrowly specialized use. Peculiarities of terms, as well as their translation into Ukrainian were studied by such linguists as G. Bezhenar, I. Beloded, I. Volkova, M. Volodina, B. Golovin, V. Danylenko, A. Dyakov, T. Kiyak, R. Korobin, D. Lotte, A. Naumenko, O. Oguy, E. Pirikov and others.

Terms, as specific lexical units of language, are characterized by such features as accuracy, unambiguity, systematicity, objectivity and motivation.

Translation of complex terms consists of two main procedures - analytical and synthetic. An important role in the translation of phrases is played by the analytical stage - the translation of its individual components. And for this it is necessary to correctly define the components of a complex term, because they can be not only words but also phrases that are part of a complex term.

The main means of translating terms-phrases are descriptive method, transcription and tracing. The most difficult to translate are terms that have different meanings not only in different fields of science and technology, but even in one field.

The main problem of translation of terms and terms-phrases is their ambiguity not only among different branches of science, but also within

\footnotetext{
${ }^{1}$ Candidate of Pedagogical Sciences, Senior Lecturer at the Department of Theory and Practice of Translation, Petro Mohyla Black Sea National University, Ukraine

(C) Yuliia Sydorenko
} 
the technical field itself. Terms are units of language and professional knowledge that ensure the effectiveness of intercultural communication. For this reason, the greatest practical significance in the translation of scientific and technical texts is the equivalent translation of terminology. Differences in the lexical structure and morphosyntactic structure of terms have objective linguistic reasons: English terms, the structure of which includes a substantive defining component (noun or noun group), cannot be translated into Ukrainian without differences in morphosyntactic structure due to differences in the grammatical structure of languages.

\section{Introduction}

In recent years, due to informational explosion, the expansion of political, economic and scientific ties of Ukraine with other countries, the flow of new English-language information is growing rapidly. We learn about the achievements of science, technology and economics, news of culture and politics in the world through English-language publications, radio, television, the Internet. Therefore, it is not surprising that the interest of linguists, as well as specialists in various fields of science and technology to the problems of English terminology is constantly growing. This is due to the ever-increasing flow of English-language information from a variety of fields of knowledge, as well as the processes of international integration and communication. An important feature of the current stage of scientific and technological progress is the mutual penetration of special terminology from one field to another, as well as more active use of special terms in texts that are addressed not only to specialists but also to a wide range of readers. Thus, the problem of translating scientific and technical terms into Ukrainian is very relevant.

The relevance of the study is due to the need to ensure accurate and adequate translation of technical documentation. It should be noted that the features of terminological units, as well as their translation into Ukrainian have been studied by many linguists, among them G. Bezhenar, I. Beloded, I. Volkova, M. Volodina, B. Golovin, V. Danylenko, A. Dyakov, T. Kiyak, R. Korobin, D. Lotte, A. Naumenko, O. Ogui, E. Pirikov, and others. But at the same time, many issues related to the terminology of individual industries, as well as the problem of compiling special dictionaries remain unresolved. The works of these scientists served as a theoretical basis for this 
work. The main Ukrainian and English terminologies were identified and certain translation methods were analyzed. However, technical terminology is a class of lexical items, which is constantly updated due to the rapid development of scientific and technological progress and the development of new technologies. Very often, traditional methods of translation are unsuitable for the transfer of modern terms. Scholars also considered the grammatical and stylistic features of scientific texts, which determine the choice of ways of their translation.

In addition, when translating technical terminology, it is necessary to take into account such a phenomenon as the asymmetry of lexical and semantic systems of two different languages - Ukrainian and English, which leads to hypero-hyponymic connections between units of source language and translation language. Unfortunately, this aspect has not been given enough attention to in the translation of technical terms in modern translation studies.

\section{Informational explosion}

Information explosion is a sharp increase in the amount of information that a person must perceive, store and use in the course of his work, it is a consequence of the scientific and technological revolution (STR) [3].

Technological culture is the fourth universal culture. It determines the worldview and self-understanding of modern man. At the same time, universal cultures are understood as systems of principles characteristic of a certain epoch and certain levels of development of scientific knowledge and technical means.

At the present stage, STR has grown into a technological revolution. Instead of the traditional for the machine industry, a qualitatively new technological method of production is being created - a fundamentally different set of methods for making useful things. In other words, STR generates «high technology» that provides a much higher level of efficiency.

Modern technologies and their objects are very complex, which determines their high scientific and information capacity, the impossibility of their formation and development without a solid scientific base, without scientific and informational search. These technologies are usually based on the latest advances in basic sciences and interact with them. They often present science with complex problems that can be solved only on the basis 
of the integration of a number of natural, mathematical, technical and social sciences. During their formation, new connections are established between science and technology.

Today, in the first place in this series came purely pragmatic considerations. On the one hand, such problems as the rapid growth of the world's population, the reduction of population growth and aging in industrialized regions, the depletion of natural resources, and environmental pollution have become more acute than ever and have become global in nature. On the other hand, there are certain preconditions for solving many global problems on the basis of scientific and technological progress, their accelerated implementation in the economy [3].

The observed interest has a clear economic component. Difficulties of industrial development, intensification of competition in the world market, limited available financial opportunities force to look for optimum ways of allocation of resources. And for this you need to clearly imagine the picture of the future. Otherwise, there is a greater danger that the effort expended will not bring the desired results. Below are the results of two forecasts prepared and published relatively recently by American and Japanese experts. They give a general idea of the main directions of scientific and technological development before the beginning of the third millennium and their possible economic consequences.

Technological breakthroughs are bright and significant events, they play a crucial role in accelerating scientific and technological progress, but there is another way, no less, and sometimes more effective, which is to combine this technology with some other [8].

The combination of technologies is an integral element of historical development, which is incomparably more common than technological breakthroughs, a complex intertwining of technologies with its topology and hierarchy of elements is born, and any change in any node of this system, in principle, causes a wave of perturbation throughout the network.

Combinations of technologies dominate in the practice of STP over technological breakthroughs not because the former require less intellectual effort - and in this area there are their witty, extremely ingenious solutions. Success is ensured by an economic mechanism: when making a breakthrough, it is necessary not only to create new equipment to achieve the former goal in general, but also to throw out the underdepreciated old 
one. Problems of waste-free production, rational use of waste in case of their formation, ecological purity of traditional and newly developed processes are of paramount importance in our century, when raw materials are rapidly depleted, and nature protection and prevention of pollution are conditions for maintaining normal human existence in the near future especially in the distant future [3].

Thus, it is possible to draw conclusions about the causes and consequences of the informational explosion. The reasons can be considered a sharp increase in information under the influence of the scientific and technological revolution. The consequences of the information explosion are the spread of new technologies in human life, as well as the entry into the language of new terms that describe new human achievements.

\section{Analysis of approaches to defining the concept of term in linguistics}

It is known that, speaking of terminology, linguists distinguish between: a) the science of terms; b) professional vocabulary in the composition of all words of the language or c) special vocabulary that serves a particular field of science or technology.

There is also no generally accepted definition of the term «term» in linguistics. This is due to many factors. The term is an integral part of a system, if the system is understood as a set of elements of the whole, between which there is a mandatory and strong connection. Thus, systematicity is one of the most important conditions for the existence of the term. A term can exist only as an element of a terminological system, if the latter is understood as an ordered set of terms that adequately express the system of concepts of theory that describe a particular field of human knowledge or activity [13].

Production activity requires direct communication between the people employed in it. The means of this communication, exchange of ideas, means that help to promote the development of certain industries, is a single national language with its grammatical structure, basic vocabulary and special, professional vocabulary.

The emergence and development of professional vocabulary is associated with the specialization of human production. The more developed a particular branch of production, science and technology is, the more it has special terms, and the richer is its terminology [18]. 
Terminological vocabulary, which is a part of the vocabulary of the language, still differs significantly from the commonly used. Moreover, some linguists also distinguish between scientific and technical terminology. Thus, J. Vinier and A. Martin emphasize that this difference is due to the very circumstances of science and technology, as technology arose as a result of a long series of trials, often conducted at random, through empirical searches and errors; science developed in its own way and, freeing itself from the original mystical and religious ideas, only at the beginning of the 19th century, thanks to its new achievements, was able to give a new impetus to the spread of technical knowledge. Therefore, «it cannot be taken for granted that science and technology belong to the same field of thinking and in their language can be expressed by the same linguistic means... In each case, the language uses different concepts and its own syntactic means» [11, p. 11].

At the same time, it should be recognized that in the era of rapid development of science and technology, these two areas of human activity develop in parallel, complement each other, mutually enrich each other, which is also manifested in the interpenetration of the features of their languages. Today it is more logical to assert the existence of the language of science, within which the language of technology is contained.

M. Zubkov notes that scientific concepts are defined by special words - terms that form the basis of scientific language. A term is a word, or established phrase, that clearly and unambiguously denotes a scientific or special concept. The term does not refer to the concept as an ordinary word, but on the contrary, the concept is attributed to the term, added to it. This difference is seen in the well-known conventionality of the term, which consists in the fact that scientists or specialists in a particular field agree on what to understand and what concept to invest in a term. Thus, the specific meaning of the concept defined by the term will be clear only through its definition - a concise, logical definition, which indicates the essential features of the subject, or indication of the concept, i.e. its meaning and limits [6].

E.Pirikov understands the term as «a word or group of words that has a specific and unique meaning within a particular field or specialization, which excludes any possibility of another understanding or interpretation that would differ from the understanding provided by the author» [13, p. 23$]$. 
Thus, referring to the dictionary of linguistic terms, by the term we mean «a word or phrase that expresses a clearly defined concept in a particular field of science, technology, art, socio-political life, etc.» [13, p. 306-307]. This definition was taken by us as the main one.

The specificity of terms is that they are unambiguous within the terminological system in which they are used, are not related to the context and are stylistically neutral.

Scientific and technical terminology is a wide layer of vocabulary that develops intensively and actively interacts with other layers of the vocabulary of the language, primarily with common vocabulary. Therefore, the study of the laws of formation of terminological vocabulary, its structure and semantics is one of the important tasks of modern linguistics, including translation studies.

All this contributed to the emergence of a new discipline in the depths of modern linguistics - terminology, which gradually clarifies its independent functions at the intersection of several sciences - linguistics, logic and relevant scientific and technical specialties.

The modern language of science and technology makes several demands on deadlines. The most important of them are the following:

- the term must comply with the rules and regulations of the relevant language;

- the term should be systematic;

- the term is characterized by definiteness, i.e. each term is compared with a clear separate definition, which focuses on the relevant concepts;

- the term is characterized by relative independence from the context;

- the term must be accurate;

- the term should be short, although this requirement often contradicts the requirements of accuracy, i.e. completeness of the term;

- the term should strive for unambiguity within one terminological system;

- the terminology is characterized by synonymy;

- terms are expressively neutral [16].

A term is an unisolated, dependent unit of commonly used language, the qualities of which are inherent in other units of the language and form a full part of the general structure of speech, the properties of which are more definite and meet the requirements of professional communication and understanding. 
Traditionally, the term means a word or phrase that means the concept of any special field of knowledge or activity. Terms are «units of natural or artificial language (words, phrases, combinations of words and letterssymbols, combinations of words and numbers-symbols), which have a special conscious collective agreement with special terminological meanings, fairly accurately and fully reflecting the basic features of relevant concepts» [10, p. 9].

A. Ivanov understands terms as «words or phrases of special (scientific, technical, etc.) language, created (borrowed) for the exact expression of special concepts and their definitions» $[7$, p. 88].

A term is a special emotionally neutral word or phrase adopted in a certain professional field, used in special circumstances. The term conveys the name of a well-defined concept relating to a particular field of science and technology. In the special literature, terms carry the main semantic load, occupying the main place among other general literary and official words. The term is also defined as «a word or phrase (created on the basis of contractual relations), which has a professional meaning that expresses the concept used in the process of learning and mastering a certain range of objects and relationships between them in terms of a particular profession» [5, p. 54].

A. Schukin notes that in contrast to commonly used words, terms are usually unambiguous, they are not characterized by expression. Some terms have lost a purely special character and are widely used in various parts of speech, while others retain a narrowly specialized use. A word that acts as a term often has an equivalent in another language, its semanticization is carried out through translation [18].

Terms are special words. The meaning of the term can be represented as a special, stylistically limited lexical meaning of the word. By definition of L.Barkhudarov, the term is a word or phrase associated with a concept belonging to a field of knowledge or activity [2]. The affiliation of a term to a special vocabulary is secondary, the term, first of all, belongs to the general class of lexical units.

The term is a member of a certain terminological system, which refers to a particular field of science, technology, production, and its conceptual meaning is determined by its place in the system. Each term has its own definition (exact scientific definition) along with other terms in the same 
field. Terms, in contrast to "everyday» words, within their terminological field are usually unambiguous: the same word can be a term of different fields of knowledge, but it is not polysemy, but homonymy. Terms, as opposed to general vocabulary, are related to a certain scientific concept: they reflect the results of scientific research and their theoretical understanding.

The meaning of the term reflects a special concept in its entirety, i.e. with all its features. To introduce a special concept means to list all the features of this object. Thus, a term is a sign used on the day of the name of a special concept, and it, in turn, is the object of reality.

The scientific literature has studied in detail the specific features of the terms, such as the presence of a definition, a close connection with the concept, the tendency to monosemy, lack of expression, stylistic neutrality [15]. Like any word, a term means a concept, which in turn is a representation of an object, an object called a word-term. But unlike an ordinary word, a term means a special concept that reflects the named object of reality in its entirety, while an ordinary concept is only a general representation of an object.

The term usually means a specific special concept, and in this sense the term is unanimous. At the same time, you can find several definitions of the same term in the dictionary. The presence of several definitions is usually the result of using the term to name special concepts that are part of different conceptual systems and subsystems. Terminological ambiguity is easily removed, because it is enough to determine the system or subsystem to which the term refers, and in this system, this sign will have only one meaning.

In fact, not all terms meet this requirement even within one specialty. This fact presents difficulties for accurate understanding of the text and makes the work of the translator difficult [15].

Directly related to unanimity is the inverse requirement that each concept correspond to only one term, that is, that there be no synonymous terms with matching meanings. Obviously, the exact identification of objects and concepts is complicated when the same thing is called differently, and there is even possible confusion over naming the same phenomenon in different words. Thus in terminology it is often necessary to face the phenomenon of synonymy. In the fine arts, the term color has several synonyms for both meanings: hue, shade, tint, tinge for the first meaning «color» and paint, tint, dye for the second meaning «paint». 
However, V. Yeliseyeva notes that even in terminology, absolute synonyms exist for a relatively short time. Then there is a redistribution of sem within the members of the series and synonyms begin to differ in scope (term, stylistic color, etc.), or acquire a new semantic nuance depending on the compatibility with other words. In the first case, they become stylistic, in the second - relative (or partial) conceptual synonyms. Examples of the formation of stylistic synonyms are the distribution of the spheres of functioning of the nouns valley and dale with the meaning «valley» [9].

It is impossible to draw a clear line between the terms and words of everyday language due to the ambiguity of these words. For example, the well-known words that are often used: atom, plastic, vitamin, antibiotic, are not terms in common language, where scientific or technical principles play a secondary role. On the other hand, simple words such as water, earth, flame, liquid, pressure are terms in a scientific or technical context when they carry a basic meaning.

The terms reflect the most accurate, concentrated and economic definition of a scientific or technical idea. For example, the term water is a scientific definition of a chemical bond whose molecule consists of two hydrogen atoms and one oxygen atom. The complex relationship between the words of common language and terms, according to O. Pumpyansky, complicates the identification of terminology of certain branches of scientific and technical literature [12].

Terminology (as a set of terms) is an autonomous sector of any national language closely related to professional activities. The terms of each branch of science, technology, production form their own systems, due primarily to the conceptual connections of professional knowledge, if you want to express these connections through language. Terminological vocabulary makes it possible to most accurately, clearly and economically present the content of the subject and provides a correct understanding of the essence of the issue.

The systematic nature of the term can be traced through other special concepts that are present in its definition. Any definition begins with a generic concept, because to define any concept means to bring it under a broader. For example, the technical terms machine and engine are defined through the generic concept of device (mechanism, device), which allows them to refer to the conceptual system devices, but they will occupy different places 
in this system, because they will have other features different: machine - «a device that converts heat or other forms of energy into mechanical energy», and engine - «a device that performs mechanical work».

As terms we can use both words used exclusively within this style, and special meanings of common words. The terms should provide clear and precise indications of real objects and phenomena, establish an unambiguous understanding by specialists of the information transmitted. Therefore, this type of words has special requirements, according to which the terms have specific features and characteristics that distinguish them from other words of the language.

It is correct to distinguish between «professionalisms» and «terms», which together constitute the concept of a special subtext. Arranged next to each other, terms are more orderly and normalized, while professionalisms are semi-official lexical units used by a narrow circle of specialists, and only in colloquial speech. Professional vocabulary is words and speech expressions that are used by representatives of certain professions, but do not belong to the terms [16].

Thus, professionalisms are words that are characteristic of the language of people of certain professions. Since professionalisms are used to denote certain concepts only in the field of a particular profession, craft, craft, they do not always meet the norms of literary language. Professionalisms act as unofficial synonyms for terms. Among the professionalisms can be distinguished scientific and technical, professional and industrial, and others. They are quite diverse in terms of semantic characteristics.

Unlike terms, professionalisms do not have a clear scientific definition and do not constitute a holistic system. If terms are usually abstract concepts, then professionalisms are specific, because they differentiate in detail those objects, actions, qualities that are directly related to the field of activity of the profession.

For the most part, professionalisms are used in the oral informal speech of people of a certain profession. Performing an important nominativecommunicative function, they accurately name a part of a product, a part of a technological process or a certain concept and thus promote better mutual understanding (flash drive - memory card, Axis - Operating System). In written language, professionalism is used in publications intended for professionals (booklets, instructions, advice). 
Professionalism, as it is known, is also used in the literature in order to create a professional color, to reproduce the life of a particular professional environment in their works [6].

Terms, as specific lexical units of language - members of the terminological system, are characterized by the following features: accuracy, unambiguity, systematicity, objectivity, motivation.

It is clear that in scientific and technical materials not only special vocabulary is used. They contain a large number of common words that are used in any functional style. When translating such lexical items, the translator faces the same difficulties and uses the same techniques to overcome them as translators of fiction. In scientific and technical materials there are also lexical elements that are more characteristic of the conversational style, in the transfer of which the translator has to face the need to choose expressive and stylistic options. Therefore, it is not enough for a translator of scientific and technical literature to have knowledge only in the field of terminology and special vocabulary. Like any translator, he must have a good command of all the richness of the languages he has to deal with [9].

The question of classification of terms is extremely important in solving problems of their translation. However, it should be noted that a single classification of terms does not currently exist, because scholars classify these lexical items on various grounds. The most common grounds for classifying terms are the following: source of origin of terms; scope of terms; the structure of terms.

\section{Terms as unites of translation}

Due to its specific features, terminological vocabulary causes objective difficulties in the translation process. When referring to the term as an object of translation, it is necessary to touch upon such areas of knowledge as translation theory and practice, information theory, linguistics, etc.

As noted by I. Alekseeva, the terms are «...self-regulating lexical apparatus, specially developed for the transmission of cognitive information» [1, p. 167]. As it was mentioned above, terms are unambiguous, have no emotional color and are independent of the context. These three important features of terms lead to conclusions that are crucial for the translator: to reproduce the terms in the scientific text should be used unambiguous, 
independent of the context of correspondence - equivalents. Many of the equivalents are contained in bilingual special dictionaries. Replacing terms with words close in meaning is not allowed.

A. Ivanov believes that only those terms that are new to the language into which they are translating and reflect new concepts can be non-equivalent. It is clear that «as the same areas of knowledge or material culture develop in the society into which the translation is made, this inequality gradually disappears» $[7$, p. 88].

Translation with a dictionary of unfamiliar terms will not be difficult. It is another matter when several Ukrainian terms correspond to one English term, for example switch; switch. In this case, the choice of analogue can be dictated only by good knowledge of the subject. In order to properly understand a special text that contains terminological vocabulary, it is necessary to know well the subject and related English terminology. In addition, in order to properly convey the content of the text in Ukrainian, it is necessary to know the relevant Ukrainian terminology and a good command of the Ukrainian literary language.

Non-equivalent vocabulary is defined as «units of the source language that do not have regular correspondences in the language of translation» [9, p. 148]. Despite the differences in the translation of non-equivalent units, they are also matched depending on the method of translation. For the translation of non-equivalent terms can be used such methods as: borrowing (by transliteration or transcription), tracing, descriptive translation, approximate translation, analog translation. Taking into account that the term is, first of all, a word, but, considering the peculiarities of its differences from the latter, three categories of correspondences are distinguished for translation:

- equivalents;

- variable and contextual correspondences;

- all kinds of translation transformations.

The most optimal for the translation of terms at the lexical level are equivalents, borrowed by transcription and transliteration, tracing, lexical substitutions (generalization, concretization).

The greatest degree of equivalence is observed in those cases when the word in translation corresponds to the translated word in other components of the content, has the same stylistic characteristics. This is often achieved 
when translating terms that have terminological correspondences in the language of translation [9].

The most commonly used means of translating terms that have no equivalent in the language of translation are borrowing, tracing, and descriptive translation.

The use of borrowing (for example, motor, diesel, radar) ensures the preservation of the main characteristics of the term, and, in addition, borrowing terms from the original language provides unification of the metalanguage of this science at the international level. However, when translating English terms into Ukrainian, it is necessary to avoid unnecessary borrowing and unnecessary use of foreign words, preferring Ukrainian words, such as «сільське господарство» instead of «агрокультура».

A. Fedorov points out that «regardless of the foreign language from which the translation is made, the principles of style reproduction are crucial in choosing options for the transfer of individual words (including terms), phraseology and syntactic inflections» $[17$, p. 299]. This also applies to cases where "the translator first encounters a new foreign term, which is not yet expressed in dictionaries, has not been found in other texts and requires accurate decipherment by logical-linguistic analysis of the word and its connection with the context and construction of accurate unambiguous correspondence (at least in the form of an extended phrase)» [17, p. 300].

To the first group of borrowings A. Fedorov refers borrowings, i.e. those that cannot be replaced by words of the native language and have already entered its vocabulary (international words first of all), and those that have only incomplete synonyms in this language, and contribute to the concept they express a special clarifying shade (for example, the word «articulation» as a phonetic term meaning the work of speech organs to produce sound and is not equivalent to the word «pronunciation» because it is broader in meaning) [17].

Borrowings that are allowed in a particular context because of their greater brevity than the corresponding synonymous means of the mother tongue, or the need for synonym variation, are used in cases where one borrowed word can replace the whole phrase in the mother tongue and therefore prefers more compactness.

The translator's choice of one of the options - Ukrainian or borrowed to convey the original meaning of the word does not remain a matter of 
taste or random decision, but expresses its relationship to the possibilities of language. It is clear that one case of choosing one or another option is not yet decisive, but the system itself is important, which is followed by the translator (as much as the author of the original), following one or another trend. The degree of acceptability of the borrowed term is also important, even in the presence of a Ukrainian synonym. Thus, the term modulation has now taken root in the theory of translation [17].

Tracing is a reproduction of the internal semantic structure of the original term, for example, high-speed - високошвидкісний, cardio-vascular серцево-судинний.

Descriptive translation is especially often used when it is necessary to convey to the addressee the meaning of a term that has no equivalents in the language of translation, for example, digital watch - годинник з цифровою індексацією, genetically modified food - продукти харчування на основі генетично модифікованих організмів.

At the same time, there are frequent cases of combining the means used in the translation of one terminological unit. The presence of several translation options confirms the focus of the dictionary on the user with minimal knowledge in a particular area, or indicates the presence of new unstable terms, the best translation option which has not yet been finally selected.

All of the above applies to the translation of any English terms into Ukrainian. However, when translating such a variety as multicomponent terms, there are additional difficulties. The problems that arise when translating English multicomponent terms into Ukrainian are mainly related to differences in the composition of these languages. In English - which is analytical - the components of the terms are interconnected positionally, without morphological design. In the Ukrainian language - which is synthetic - the components must be connected not only positionally, but also with case endings.

The simplest case is the translation of such terms, where each prepositional component can be considered as a definition of the main word in the phrase. This method of translation is called elemental, for example, one-electron bond - одноелектронний зв'язок [10]. The simplest way is to translate with the help of a Ukrainian term of a similar model, when the dependent components of the term-phrase are translated as a definition. 
The same model translates non-equivalent terms formed in this way, for example, analog computer - аналоговий комп'ютер.

In more complex cases, a genetic model of translation is used, i.e. a definite noun in the genitive case, for example, grapefruit seed oil - олія насіння грейпфрута. Sometimes the translation may require a permutation of the components of the term: cybernetic chemistry era-ера кібернетичної ximiï. Quite often when translating one multicomponent term, two or more tools are used simultaneously. For example, when translating the term water vapor pressure - тиск водяної пари, two methods were used: the dependent component water was translated as «водяна», and the dependent component vapor was translated by the Ukrainian equivalent in the genitive case «пари» [10].

An effective and widely used means of translating English multicomponent terms that have no vocabulary equivalents in the Ukrainian language is a description. Descriptive translation allows you to convey in Ukrainian a concept that is expressed in a non-equivalent term, for example, money market - короткострокова позика між банками (a short-term loan between banks).

Translation of English multicomponent terms is impossible without a careful analysis of their components and the relationship between them. The most typical ways of translating English multicomponent terms into Ukrainian are translation using:

- Ukrainian multicomponent term of similar model;

- Ukrainian multicomponent term formed by permutation of components;

- Ukrainian multicomponent term, which includes a preposition;

- Ukrainian multicomponent term formed with the help of adverbial and adverbial constructions;

- descriptive translation [10].

The literature on translation problems offers a large number of different ways and means of transmitting English terms in Ukrainian. The choice of translation depends on the type of text and the novelty of the term. In special texts, preference is often given to borrowing the term (transcription or transliteration), sometimes tracing. If it is a translation of an article from a regular journal, and not a special edition intended for specialists, you can use a descriptive translation or borrowing, or tracing with an explanation in the text or in a footnote [17]. 
Having researched theoretically the question of technical terms translation into the Ukrainian language, we came to the following conclusions:

The term is a word or phrase that expresses a clearly defined concept in a particular field of science, technology, art, socio-political life and so on. The set of terms as lexical means of naming is terminology.

The translation of English terms into Ukrainian requires knowledge of the field to which the translation relates, understanding of the meaning of terms in English and knowledge of terminology in the native language. When translating scientific and technical literature from English into Ukrainian, the interaction of the term with the context is important, due to which the meaning of the word is revealed.

In technical terminology there are mostly complex terms and phrases. Translation of complex terms consists of two main procedures - analytical and synthetic. An important role in the translation of phrases is played by the analytical stage - the translation of its individual components. And for this it is necessary to correctly define the components of a complex term, because they can be not only words but also phrases that are part of a complex term. It is also important to establish in what semantic relations the components are among themselves and with the main component of the term-phrase.

The main means of translating terms-phrases are descriptive method, transcription and tracing. The most difficult to translate are terms that have different meanings not only in different fields of science and technology, but even in one field. Such a word, which has several vocabulary correspondences, variants similar to it in meaning, is translated by selecting the variant-analogue, which would most accurately convey the meaning of the term depending on the words that are closely related to it.

In general, technical terms have the same means of translation from English to Ukrainian as all other terms. The main problem of translation of technical terms and terms-phrases is their ambiguity not only among different branches of science, but also within the technical field itself.

\section{Conclusion}

Terms are units of language and professional knowledge that ensure the effectiveness of intercultural communication. For this reason, the greatest 
practical significance in the translation of scientific and technical texts is the equivalent translation of terminology.

Differences in the lexical structure and morphosyntactic structure of terms have objective linguistic reasons: English terms, the structure of which includes a substantive defining component (noun or noun group), cannot be translated into Ukrainian without differences in morphosyntactic structure due to differences in the grammatical structure of languages.

After conducting scientific research on means of translation of English terms in Ukrainian, we found that they are somewhat different, but none of the scholars provide detailed instructions on the translation of terms, as they are a special group of scientific and technical vocabulary. The translator must not only be fluent in English, but also be proficient in the specific field to which the text of the translation belongs, as the meaning of the terms is closely linked to the context, content and specificity, and may vary depending on the field of use. Only with an effective combination of these two conditions can an adequate translation of any scientific and technical literature be made. Further work is in practical research of the specified methods of translation in the course of translation of automobile terms.

\section{References:}

1. Alekseeva I.S. (2004) Vvedenie v perevodovedenie [Introduction to translation studies]. SPb.: Filologicheskij fakul'tet SPbGU; M.: Izdatel'skij centr «Akademiya».

2. Barhudarov L.S. (1975) Yazyk i perevod. Voprosy obshchej i chastnoj teorii perevoda. [Language and translation. Questions of general and specific translation theory]. M.: Mezhdunarodnye otnosheniya.

3. Bilozerska L. P. (2010) Terminolohiia ta pereklad [Terminology and translation]. Vinnytsia: Nova kn.

4. Vakulenko M. (2015) Ukrainska terminolohiia: kompleksnyi linhvistychnyi analiz [Ukrainian terminology: complex linguistic analysis]. Ivano-Frankivsk: Foliant.

5. Volodina T.S., Rudkivskyi O.P. (2017) Zahalna teoriia perekladu dlia pershoho (bakalavrskoho) rivnia [General theory of translation for the first (bachelor's) level]. K.: Vyd. tsentr KNLU.

6. Golovin B.N. (1983) Vvedenie v yazykoznanie [Introduction to linguistics]. M.: Vysshaya shkola.

7. Zubkov M. (2002) Suchasna ukrainska dilova mova [Modern Ukrainian business language]. H.: Torgin.

8. Ivanov O.A. (2006) Bezekvivalentnaya leksika [Non-equivalent vocabulary]. SPb.: Izd-vo S.-Peterb. universiteta. 
9. Karaban V. (2002) Pereklad anhliiskoi naukovoi i tekhnichnoi literatury. Hramatychni trudnoshchi ta zhanrovo-stylistychni problemy [Translation of English scientific and technical literature. Grammar difficulties and genre-stylistic problems]. Vinnytsia: Nova knyha, 315-407.

10. Kyiak T.R., Ohui O.D., Naumenko A.M. (2006) Teoriia ta praktyka perekladu [Theory and practice of translation]. Vinnytsia: Nova knyha.

11. Mihajlova V. (1991) Struktura mnogokomponentnyh terminov himii i ih perevod s anglijskogo yazyka na russkij [The structure of multicomponent chemistry terms and their translation from English into Russian]. L.: Izd-vo RGPU im. A.I. Gercena.

12. Nazarov V. (2000) Kurs ekonomicheskogo perevoda [Economic translation course]. M.: MGU.

13.Pumpyanskij A. (1981) Vvedenie v praktiku perevoda nauchnoj i tekhnicheskoj literatury na anglijskij yazyk [Introduction to the practice of translating scientific and technical literature into English]. M.: Nauka.

14. Pyrikov E. (1992) Kommunikativnye aspekty perevoda i terminologii [Communication aspects of translation and terminology]. M.: VGSHCH.

15. Savchuk M. (2008) Anhlo-ukrainskyi naukovo-tekhnichnyi slovnyk [English-Ukrainian scientific and technical dictionary]. K.

16. Superanskaya A.V., Podol'skaya N.V., Vasil'eva N.V. (2007) Obshchaya terminologiya: Voprosy teorii [General Terminology: Theoretical Issues]. M.: Izd-vo LKI.

17. Terekhova G. (2004) Teoriya i praktika perevoda [Translation theory and practice]. Orenburg: GOU OGU.

18. Fyodorov A. (2002) Osnovy obshchej teorii perevoda [Fundamentals of General Translation Theory]. SPb.: SPbGU.

19. Shchukin A. (2007) Lingvodidakticheskij enciklopedicheskij slovar' [Linguodidactic Encyclopedic Dictionary]. M.: Astrel': ACT: Hranitel'. 